\title{
Áreas verdes y arbolado en Mérida, Yucatán. Hacia una sostenibilidad urbana
}

\section{Green spaces and urban trees in Merida, Yucatan. Toward urban sustainability}

\author{
Susana Pérez-Medina* \\ INA LÓPEZ-FALFÁN**
}

\begin{abstract}
Green spaces and tree cover are essential components of ecological, social and economic urban sustainability. This paper analyses the green areas in Mérida and the conditions that determine their creation and distribution. The methodology was based on satellite imagery analysis for the cover tree, Google Earth to measure and calculate areas, and field visits. The results point to a strong association between housing typology, urban management, governance and social participation.
\end{abstract}

Keywords: green spaces and tree cover, sustainability, housing tipology, urban management, governance.

\begin{abstract}
Resumen
Las áreas verdes y el arbolado son parte esencial de las dimensiones ecológica, social y económica de la sostenibilidad urbana. La presente investigación es un análisis de las áreas de vegetación en Mérida y de las condiciones que determinan su presencia y distribución. La metodología se basó en el procesamiento de imagen de satélite para captar la cobertura arbórea, se uso Google Earth como herramienta para medición y cálculo de superficies y recorridos de campo. Los resultados arrojan que las áreas verdes y cobertura arbórea se vinculan al mercado de vivienda y sus tipologías, a los procesos de gestión y gobernanza, y a la participación social.
\end{abstract}

Palabras clave: áreas verdes y arbolado, sostenibilidad, tipología habitacional, gestión urbana, gobernanza.

*Centro de Investigación y de Estudios Avanzados, unidad Merida. Correo-e: sperez@mda. cinvestav.mx

**Universidad Nacional Autónoma de México. Correo-e: ina.lopez@posgrado.inecol.edu.mx, isfalfan@yahoo.com.mx 


\section{Introducción}

Las ciudades como territorios donde se concentran las actividades humanas son, a la vez, los centros de mayor demanda de recursos naturales y los que producen la mayor cantidad de desechos. Mérida, capital de Yucatán, no es la excepción.

La sostenibilidad urbana se define a partir de los efectos que las actuales formas de producción y consumo tienen sobre el medio ambiente, pero también sobre las relaciones con los grupos sociales. Las áreas verdes constituyen uno de los mecanismos que coadyuvan a la sostenibilidad en las ciudades. Sus aportaciones no sólo se asocian al medio ambiente sino que contribuyen a crear una interacción social más saludable. En esta investigación examinamos las condiciones de sostenibilidad y arbolado que caracterizan a Mérida actualmente.

Por áreas verdes urbanas se entiende las zonas con árboles, arbustos y otros tipos de vegetación. La presencia y densidad de áreas verdes se asocia a la gestión urbana, y es en ésta donde se desarrollan las políticas de suelo vinculadas a los procesos de construcción y ordenamiento de la ciudad, y también donde se configuran las tipologías habitacionales y el contexto normativo de las áreas verdes.

El presente trabajo es un análisis de las áreas verdes en la ciudad de Mérida en la actualidad y de las condiciones que determinan su presencia y distribución. Asimismo, se se enfoca este estudio en cuatro asentamientos habitacionales con particulares tipologías de vivienda emplazados en diferentes zonas de la ciudad. Elementos que se analizan bajo la perspectiva de la sostenibilidad urbana.

La metodología para la cobertura arbórea se basó en el procesamiento de una imagen satelital Landsat ETM del 2000 aplicando una resolución espacial de 30 metros. En el estudio se realizó una clasificación supervisada con las cuatro primeras bandas ETM (azul, verde, rojo e infrarrojo cercano), que arrojó una imagen de un índice de vegetación normalizado (NDVI, por sus siglas en inglés) mediante el método de máxima verosimilitud y con un porcentaje mínimo de probabilidad de 90\%. A partir de esta clasificación se extrajo únicamente la clase de arbolado urbano para su cuantificación y asociación con variables como densidad de vivienda, densidad de población, tipología de vivienda y etapas de crecimiento de la ciudad.

Para los estudios en los asentamientos habitacionales se hicieron recorridos de campo para evaluar los equipamientos, vialidades y tipologías de la vivienda relacionadas con la vegetación, así como para observar y valorar los usos que los diferentes grupos sociales hacen de las áreas verdes. Se utilizó Google Earth como la herramienta principal para la medición 
y cálculo de las superficies de los equipamientos, de las áreas verdes (incluyen las áreas de pasto, arbustos y árboles) y de la totalidad de los fraccionamientos.

Cabe aclarar que la imagen satelital con la que se analizó la cobertura del arbolado urbano corresponden al 2000, las imágenes satelitales de Google Earth corresponden al 2002 y el estudio de campo, la normatividad y los datos demográficos son del 2010; este desfasamiento de fechas no demeritó el proceso de análisis ni fue obstáculo para obtener resultados importantes y reveladores.

Entre los resultados más sobresalientes se tienen: a) que en las zonas de Mérida de crecimiento anterior a 1970 y las más recientes del norte y sur, donde reside población de altos y bajos ingresos, respectivamente, son más arboladas que el resto de la ciudad donde imperan los fraccionamientos de vivienda en serie; $b$ ) que la normatividad relativa a la generación, manejo y conservación de áreas verdes y jardines no es clara ni precisa y tampoco es respetada cabalmente, tampoco propicia una mayor superficie de áreas verdes, ni públicas, ni privadas y c) que en el fraccionamiento Pacabtún con 6803 habitantes y una densidad de 132.6 habitantes por hectárea, cada residente tiene $0.8 \mathrm{~m}^{2}$ de área verde pública, incluyendo parques y camellones, que se suma a la total ausencia de jardín y reducidos espacios privados. Condiciones que están lejos de llevar a una transición hacia la sostenibilidad urbana.

\section{Sostenibilidad urbana}

Las ciudades donde hoy se asienta más de la mitad de la población mundial son los principales centros de producción y consumo, y eso las convierte en territorios con alta demanda de bienes naturales que ingresan como materia prima y salen como desechos. Los trabajos publicados sobre la huella ecológica muestran los alcances de la afectación de amplios territorios debido al consumo irracional que algunas ciudades tienen sobre sus entornos y de aquellos de donde extraen recursos naturales (Girardet, 2001; Wackernagel y Rees, 1996).

Este modelo de desarrollo de la sociedad industrial moderna ha alcanzado límites que plantean problemas de viabilidad a futuro. Empero, la ciudad en sí misma no necesariamente tiene que dañar al medio ambiente, sino que realmente podría haber una relación armoniosa entre los grupos sociales y la naturaleza. El problema de la mayoría de las sociedades actuales consiste en las formas en que la gente se relaciona entre sí, en sus modelos de producción y la obsesión desarrollista y su contraparte indispensable, el afán de consumo (Harvey, 2010; Leff, 2002). 
Y precisamente, como un contrapeso para cambiar el rumbo de la ciudad desarrollista y consumista que somete a la naturaleza, se conforma la ciudad sostenible. Si bien el término de sostenibilidad surgió como referencia a una problemática centrada en los recursos naturales, hoy por hoy este sentido ambientalista ha sido rebasado al incorporar la dimensión social, ya que en la configuración de la ciudad sostenible intervienen las dimensiones sociales, ecológicas y económicas (Florino, (s.a.), James et al., 2009; Lezama y Domínguez, 2006; Sullivan, 2005). La definición más difundida de desarrollo sostenible se refiere a la capacidad que tienen algunas sociedades de producir sus bienes y distribuirlos adecuadamente en el presente, sin comprometer a las futuras generaciones. El término involucra el desarrollo de ideas y prácticas de justicia social, democracia, participación e igualdad, que todos tengan las mismas oportunidades para acceder a los recursos naturales y a la riqueza socialmente generada.

En términos ecológicos, una ciudad sostenible "mantiene vínculos estables con la región tributaria de la que extrae sus recursos y en la que descarga sus residuos" (Girardet, 2001: 53). ${ }^{1}$ La ciudad sostenible es aquella cuyo impacto al medio ambiente en contaminación y abastecimiento de bienes naturales no compromete al propio territorio ni a otros. Algunas ciudades, sobre todo en países desarrollados, tienen sostenibilidad hacia dentro, es decir, no impactan su propio territorio porque tienen sistemas productivos más ecológicos, avanzados tratamientos de desechos, uso masivo de transporte público o de bicicletas, amplias áreas verdes, etcétera.

Sin embargo, tienen insostenibilidad hacia otros territorios, pues utilizan para su producción y consumo una gran cantidad de materias primas extraídas de otras regiones, y muchas son productos no renovables (Satterthwaite, 1997), o bien, porque desplazan sus procesos productivos más contaminantes hacia otras regiones. Por otro lado, las sociedades, principalmente de países subdesarrollados, dada su escasa tecnología y capital, tienen poca capacidad para extraer materias primas de otros lugares, no impactan otras regiones pero sí su propio territorio, pues carecen de tecnologías verdes de producción y un adecuado tratamiento de residuos, como es el caso de Mérida y de la mayoría de las ciudades de los países en vías de desarrollo.

Las condiciones de sostenibilidad en las ciudades se asocian a la gestión en sus diferentes escalas políticas y espaciales, desde la global hasta la local. En el plano mundial, la problemática del calentamiento global se ha convertido en el tema prioritario de las agendas de organismos internacionales, y cada vez de más países. Paralelamente, ha habido importan-

\footnotetext{
${ }^{1}$ Esta afirmación hace referencia al concepto de bioregión (Barlett, 2005 y Girardet, 2001).
} 
tes avances en la institucionalización de la cooperación ambiental internacional debido a la certeza política de la interdependencia del equilibrio del medio ambiente (Ojeda, 1999).

Para organismos como la Organización para la Cooperación y el Desarrollo Económicos (OCDE, 2011) y el Programa de Naciones Unidas para el Medio Ambiente (PNUMA, 2011), así como para algunos autores (Girardet, 2001, Hardoy et al., 2001), las estrategias más importantes a seguir en cuestiones ambientales se centran en bajar las emisiones de carbono mediante la eficiencia del sistema de transporte, volver más limpias las tecnologías de producción, usar tecnologías alternativas de energía, el manejo eficiente de desechos y la reforestación, esta última propuesta sólo para el campo.

Sin embargo, hasta ahora los tratados internacionales han evadido los cuestionamientos al sistema económico neoliberal y su doctrina desarrollista, a pesar de las argumentaciones de algunas corrientes ambientalistas, sociológicas y políticas que señalan los efectos nocivos para los ecosistemas, el bienestar social y el desarrollo equilibrado de las diversas regiones que esta política tiene a lo largo y ancho del planeta.

Si bien los avances en materia de acuerdos internacionales ambientales es una base para mejorar las condiciones locales, es en este nivel donde se pueden aterrizar las normas ambientales internacionales. En el ámbito local es posible concretar las acciones para la sostenibilidad urbana mediante la planeación, administración, el aparato normativo y su observancia, así como por el papel que desempeñan los diferentes grupos sociales e individuos y sus relaciones, es decir, para que estas dinámicas conduzcan a la ciudad sostenible tiene que prevalecer una gobernanza efectiva (Florino, s.a.; Freire, 2007).

La gobernanza se refiere a la participación ciudadana en la elección, monitoreo y reemplazo de los gobiernos. Éstos deben tener la capacidad de implementar buenas políticas, respeto a los ciudadanos, al Estado y a las instituciones que gobiernan las interacciones económicas y sociales (Freire, 2007). Una buena gobernanza local cuida no sólo de proveer de servicios sino de preservar la vida y libertad de los ciudadanos, crear espacios y mecanismos de participación democrática y diálogo civil, apoyo al mercadeo, cuidado del medio ambiente y facilitando resultados que enriquezcan la calidad de vida de los residentes locales (Freire, 2007).

La participación de los ciudadanos, asociaciones de vecinos y organizaciones es de vital importancia en la gobernanza (Florino, s.a.; Freire, 2007). Intervención que implica el cambio de valores con respecto a la comunidad y a la política. Los ciudadanos tienen que comprometerse activamente en la definición de una visión de comunidad que involucre aspectos sociales, ecológicos y económicos; ser parte en la deliberación 
acerca de sus intereses compartidos como comunidad y en las estrategias para la promoción de sus beneficios. Lo cual significa la adquisición de capital social, el cual es necesario para que en una comunidad pueda haber gobernanza (Florino, s.a.).

\section{1. Áreas verdes y sostenibilidad}

Las zonas verdes en las ciudades aminoran los impactos al ecosistema que las actividades urbanas generan, tales como el alto consumo de energía para la producción de bienes y servicios, la intensificación del transporte, la generación de desechos, así como la formación de islas de calor, ruido, contaminación del aire y de los mantos freáticos; efectos que representan riesgos para la salud humana.

La presencia de áreas verdes y arboladas indican la calidad ambiental. La optimización de estos beneficios está directamente relacionada con la cobertura, composición, densidad, distribución y estado de salud del arbolado (NSII, 2001; James et al., 2009). Entre mayor, más densa y más saludable sea la cobertura, funcionará mejor y, en consecuencia, aumentarán las probabilidades de que provea de beneficios ecológicos (Köchli y Brang, 2005; Stabler et al., 2005; Maco y McPherson, 2002; Gómez et al., 2001; Romero et al., 2001).

Los beneficios o servicios ambientales (Coldin et al., 2006; James et al., 2009; Tyrväinena et al., 2007; Tzoulas et al., 2007) que las áreas verdes generan están ampliamente documentados: disminuyen el consumo de energía eléctrica para el enfriamiento del aire, coadyuvan a los procesos de purificación del aire, permiten un mejor desarrollo del ciclo hidrológico, la permeabilidad del suelo y la calidad del agua y aminoran el ruido (Cerón et al., 2013; Gidlöf y Öhrström, 2007; McMichael, 1999; Oliveira et al., 2011; Perry y Nawaz, 2008; Yang et. al., 2005).

Una ciudad arbolada contribuye a la biodiversidad, que es un importante indicador de ciudad ecológicamente sostenible. A mayor biodiversidad mayor equilibrio del ecosistema urbano (Colding et al., 2006; Tzoulas et al., 2007). Algunos estudios ambientales no consideran los parques, jardines y bosques urbanos como naturaleza, ${ }^{2}$ sino como segunda naturaleza porque constituyen una reproducción de las condiciones en las que se desenvuelve aquella (Fonseca, 2008; Fernández, 1994). La segunda naturaleza hace referencia a la que es construida artificialmente, modelada y estilizada, y puede ubicarse en zonas rurales y en el interior de las ciudades; de aquí que las áreas verdes hayan sido asociadas al pai-

\footnotetext{
${ }^{2}$ La naturaleza es entendida como "el conjunto de procesos en el que se desarrollan libremente la vida animal y vegetal, al margen de la actividad humana” (Hill, 2001: 226).
} 
sajismo o arquitectura de paisaje ${ }^{3}$ e incluso se han llegado a desvincular las áreas verdes de la naturaleza y de sus funciones, atribuyéndoseles cualidades ornamentales.

De acuerdo con Fonseca (2008: 149), la presencia de vegetación responde al simbolismo y a la "representación idealizada de la naturaleza, como una forma de recuperar lo perdido...”. En la dimensión social, los parques y áreas verdes destinados a la recreación, el ocio y el deporte favorecen la sensación de paz, libertad e independencia, y contribuyen significativamente a la salud física y mental y al bienestar emocional de los ciudadanos (Frumkin, 2005; Garzón et al., 2004; James et al., 2009; Neuvonen et al., 2007; Sick y Bruun, 2007; Sullivan, 2005; Tzoulas et al., 2007; Van-Herzele y Wiedemann, 2003; Ward, 2013). Otro beneficio de los espacios públicos verdes es que propician la interacción social (Newton, 2007; Whitehead, 2003), cualidad muy importante para contrarrestar las tendencias de segregación por clase social que hoy prevalecen en las ciudades, compensando la proliferación de lugares públicos privatizados, principalmente plazas comerciales.

El éxito que han tenido algunas ciudades en la planeación, creación y conservación de parques, bosques y jardines urbanos y, en consecuencia, en los servicios ambientales, sociales y en la salud que ofrecen, es atribuible, en gran medida, a la participación activa de los individuos, grupos y organizaciones no gubernamentales en las desiciones, así como al compromiso compartido con los gobiernos locales (Baycan y Nijkamp, 2009; Colding et al., 2006; Ernstson et al., 2008; James et al., 2009), es decir, prácticas de gobernanza efectiva. Experiencias que han tenido lugar en ciudades europeas. No obstante, en la gran mayoría de las ciudades de todo el mundo y de América Latina, las acciones tendentes a la oferta y distribución de parques y jardines, sus dimensiones y características específicas, tales como el tipo de vegetación y densidad se configuran en la gestión urbana, es decir, en la organización y administración de los bienes públicos y de la estructura espacial por parte de las instancias gubernamentales, mismas que responden a la demanda social. El marco normativo en el que se apoya dicha organización está constituido por leyes, ordenamientos, reglamentos, planes y estatutos, y éste rige el desarrollo de los asentamientos humanos.

La demanda social involucra los valores, actitudes y prácticas de la población relacionadas con la conformación de la estructura socioespacial; en ella se articulan los aspectos ambientales, de desarrollo social y eco-

\footnotetext{
${ }^{3}$ El paisajismo es un término frecuentemente utilizado para referirse al diseño de parques y jardines. Para efectos del presente trabajo se entiende por paisajismo el diseño urbano que involucra edificios, calles y jardines, y genera formas o escenarios que son percibidos por los usuarios de la ciudad.
} 
nómico. De acuerdo con Duhau (1998), la demanda social de los bienes públicos (entre los que se encuentran los ambientales) establece las líneas generales de la gestión urbana. Se forma con los múltiples actores de la ciudad, desde los individuos consumidores de bienes y servicios hasta los diferentes grupos con intereses particulares: empresarios, organizaciones no gubernamentales, jóvenes, etc., cada cual con sus necesidades y objetivos.

\section{Arbolado y áreas verdes en Mérida}

La ciudad de Mérida cuenta con 830,732 habitantes (Inegi, 2010) y tiene una extensión de 20,975 hectáreas (Ayuntamiento de Mérida, 2010a: 22). El clima es caluroso, ${ }^{4}$ el más seco de los cálidos subhúmedos, con régimen de lluvias de verano y presencia de canícula. Las temperaturas máximas de abril y mayo en los últimos seis años, con pocas excepciones, rebasan ligeramente los $40{ }^{\circ} \mathrm{C}$, en mayo de 2008 llegó a $42.8{ }^{\circ} \mathrm{C}$. En marzo, junio, julio, agosto y septiembre las temperaturas máximas fueron generalmente de 37 a $39^{\circ} \mathrm{C}$ (UADY, 2013). Con estos datos consideramos que sólo los meses de octubre a febrero son considerados agradables, con tendencia a cálidos.

Las temperaturas elevadas junto con la alta humedad ${ }^{5}$ son las causas principales del poco confort climático que se experimenta en la ciudad, lo que ha causado que se generalice el uso del aire acondicionado la mayor parte del ańo, cuyo funcionamiento provoca un incremento de la temperatura. Pero a pesar de las condiciones climáticas mencionadas y las funciones que la vegetación tiene en la disminución de la temperatura, específicamente, la cobertura arbórea, los parques, jardines, camellones y glorietas se ven constantemente amenazados y reducidos.

Mérida en 2010 supuestamente contaba con 5'120,925.73 m² de áreas verdes con cubierta vegetal arbolada distribuidos en 490 parques (Ayuntamiento de Mérida, 2010a: 199). ${ }^{6}$ Esta área representa un promedio de

\footnotetext{
${ }^{4}$ De acuerdo al sistema de Köppen modificado por García (2004) es Aw0(i’)gw”.

${ }^{5}$ El valor promedio mensual de humedad relativa en el periodo de 1981 a 2000 fue de $70 \%$; los meses con mayor humedad relativa fueron septiembre, octubre y noviembre (con valores promedio mensuales entre $75 \%$ y $76 \%$ ), mientras que los meses con menor humedad relativa fueron marzo, abril y mayo (con valores que van entre 63\% y 64\%) (Conagua, s.a).

${ }^{6}$ Esta cifra arroja un promedio de $10,450.8 \mathrm{~m}^{2}$ de áreas verdes por parque, lo cual no corresponde con la realidad ni siquiera considerando área verde la totalidad de la superficie de los parques, pues de ser así tendríamos una gran cantidad de parques de aproximadamente una hectárea de extensión. Sin embargo, en Mérida la gran mayoría de parques recreativos tiene entre 500 y 5,000 m², incluyendo canchas de usos múltiples, andadores y areneros (Pérez, 2010). Además, dicha cifra contrasta con el Programa de Desarrollo Urbano de 2003, el cual establece que había un total de 433 parques y $247,397 \mathrm{~m}^{2}$ de áreas verdes, lo que arroja un promedio de $571.3 \mathrm{~m}^{2}$ con vegetación por parque. En conclusión, es imposible que en siete años las áreas verdes se hayan multiplicado 20 veces.
} 
$6.9 \mathrm{~m}^{2}$ de áreas verdes por habitante, ${ }^{7}$ cantidad que se encuentra por debajo de los $9 \mathrm{~m}^{2}$ que la oms señala como mínimo por habitante (Sorensen et al., 1998), ni qué decir de los 15 que indica la Organización de las Naciones Unidas (citado por Alanís, 2005).

Es preciso mencionar que en Mérida la cantidad de árboles era considerablemente mayor antes de que el huracán Isidoro azotara la Península de Yucatán en septiembre de 2002 (López y Toledo, 2003), que principalmente derribó a aquellos que estaban enfermos o en mal estado, así como aquellas especies inadaptadas a las condiciones locales.

La distribución y densidad de la cobertura arbórea está directamente relacionada con las variadas formas de asentamientos habitacionales, que resultan del entrelazamiento histórico de varias estructuras sociales, y las mezclas y combinaciones particulares que éstas generan. Pero también depende de los actuales procesos de gestión.

\subsection{Tipología habitacional}

La tipología de vivienda (configuración resultante de la traza de las calles, la geometría de parcelación, la posición de la vivienda en el lote y la forma edificatoria) es determinante en la presencia de áreas verdes y arboladas. El primer cuadro de la ciudad -la parte que corresponde al crecimiento desde la fundación hasta 1953-, y la franja que rodea a éste, correspondiente al crecimiento entre 1953 y 1970 (figura I) tienen similitudes en la traza urbana y en la geometría de parcelación. La traza consiste en bloques de vivienda (manzanas) divididos por calles, son cuadrados de 100 metros por lado, lo que permite tener amplios solares (patios) que forman centros de manzana arbolados.

Si bien antes de 1970 ya habían varios asentamientos de viviendas en serie, fue a partir de esta década cuando inicia la construcción masiva de este tipo de conjuntos habitacionales, conocidos comúnmente como fraccionamientos, destinados a la población de ingresos medios. ${ }^{8}$

En los fraccionamientos, las manzanas dejan de ser cuadradas para convertirse en rectangulares, lo que permite acomodar las hileras de lotes de 10 metros de frente por 25 de fondo, de tal modo que los solares (patios) colindan. Con esta distribución desaparecen los centros de man-

${ }^{7}$ El Programa de Desarrollo Urbano de 2003 (Ayuntamiento de Mérida, 2003) indica cuatro metros cuadrados por habitante.

${ }^{8}$ El desarrollo del sector inmobiliario se aprecia en el Producto Interno Bruto (PIB). La participaión de la construcción en el PIB en 1970 fue de 4.21\%; en 1980, de 9.22\%; en 1993, de 6.33\%, y en el 2000, de $7.96 \%$ (Inegi, 2000 y 2010). 
zana y, en consecuencia, los espacios verdes. Con lo anterior, la tipología dominante consiste en la vivienda unifamiliar horizontal. ${ }^{9}$

Las áreas verdes se encuentran en los conos del norte, que es donde se concentra la vivienda residencial media, residencial y residencial en serie, y en el sur, donde hay un número importante de viviendas de interés social y viviendas precarias (figura I).

\section{Figura I}

\section{Cobertura de arbolado urbano y etapas de crecimiento de Mérida}

\section{2-2000}

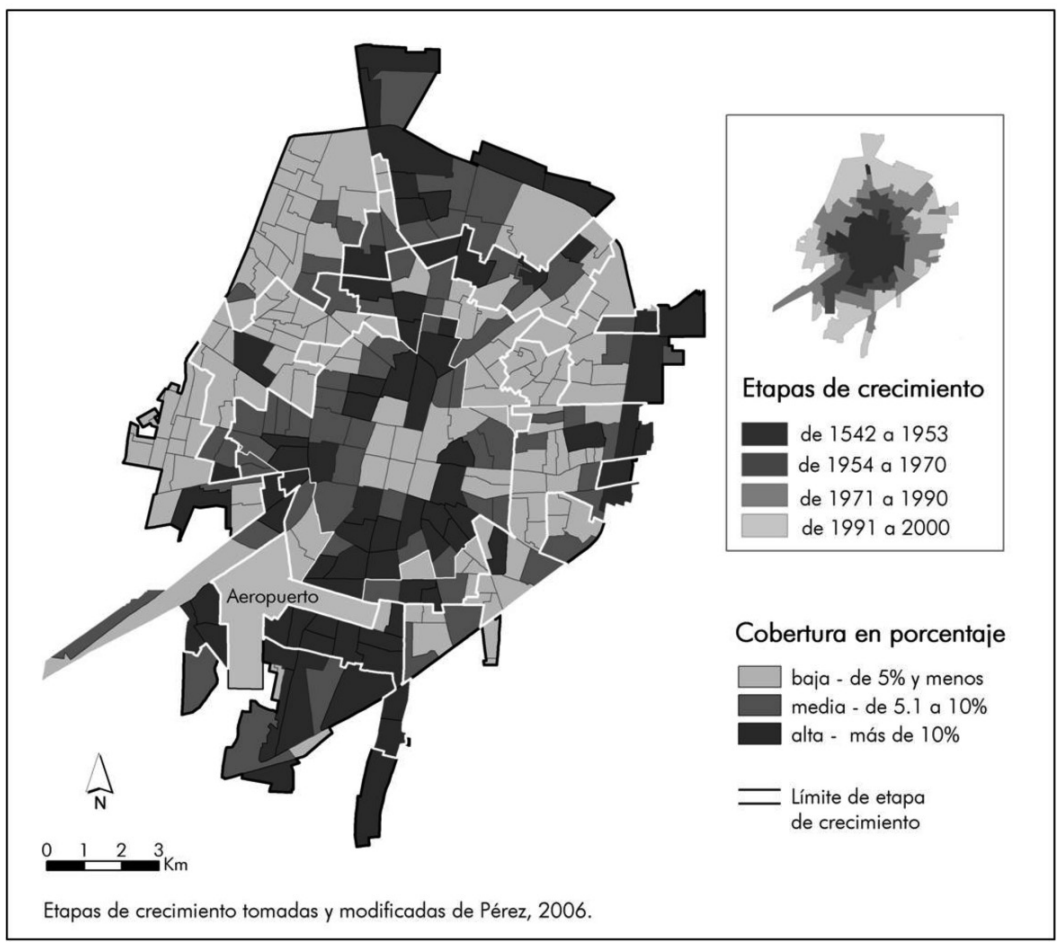

Fuente: López, 2008.

En el oriente y poniente, donde prevalece la vivienda en serie en terrenos con dimensiones mínimas, es magra la presencia de zonas verdes. Las imágenes aéreas muestran en la mayoría de los fraccionamientos, terrenos y manzanas completas de construcción un vacío total de vegetación.

Por otra parte, en el noroeste, donde se realizó una de las expropiaciones más extensas de terrenos, se construyó el fraccionamiento Francisco

${ }^{9}$ En la actualidad se están construyendo las primeras siete torres de vivienda en el norte de la ciudad, con más de 10 niveles. 
de Montejo, con aproximadamente 15 mil unidades de vivienda media $\mathrm{y}$, en segundo término, la vivienda de interés social. Asentamiento que presenta un panorama de carencia significativa de árboles.

\subsection{Distribución del arbolado en espacios públicos}

Con fines de análisis, se hizo una división de áreas verdes en públicas y privadas en función del uso, no del sector que la produce. Se consideran públicas aquellas que se emplazan en las vías de circulación y en equipamientos, y privadas, aquellas que se encuentran en los predios particulares.

$\mathrm{Al}$ igual que la vivienda, la arborización en los espacios públicos también se asocia con las etapas de crecimiento de la ciudad. El auge henequenero, de fines del siglo xix hasta mediados del xx, ${ }^{10}$ fue determinante en la estructura actual de la ciudad. La riqueza que generó el henequén permitió la construcción de una gran cantidad de equipamientos e infraestructuras, tales como hospitales, escuelas, parques, mercados, un zoológico y las avenidas Paseo de Montejo y Colón, que hoy siguen teniendo amplios espacios verdes y arbolados.

Las avenidas construidas en las últimas décadas, salvo raras excepciones (como la calle 60 norte), no se distinguen por la presencia de árboles, ya sea porque son asentamientos recientes y, por lo tanto, con árboles pequeños, o porque los espacios destinados a camellones y glorietas son muy reducidos. Otra dificultad para el sano crecimiento de árboles y vegetación en estas avenidas es el cableado aéreo de electricidad, teléfono, televisión por cable y alumbrado público que está a aproximadamente 15 metros de altura, y las compañías proveedoras de estos servicios, en coordinación con el Ayuntamiento, procuran que la vegetación no afecte el cableado.

Los equipamientos educativos, de salud, oficinas públicas y privadas construidos en las últimas décadas prácticamente no tienen áreas verdes, con excepción del nuevo hospital de Alta Especialidad. Asimismo, el equipamiento comercial de Mérida tampoco cuenta con vegetación. Tanto las plazas comerciales como los supermercados con amplias superficies de construcción y estacionamiento (algunos hasta de más de una hectárea), carecen totalmente de vegetación, y el mismo patrón se reproduce en la gran cantidad de pequeñas plazas comerciales o conjuntos de locales con estacionamiento que han proliferado por toda la ciudad.

Los parques recreativos, que son los espacios con vocación de áreas verdes, siguen la misma tendencia de los cortes de las etapas de crecimiento

\footnotetext{
${ }^{10}$ No obstante que a principios del siglo pasado se alcanzó la máxima producción y exportación de henequén, la economía de Yucatán giró en torno a la producción del agave hasta la década de 1970, cuando la actividad dejó de ser mayoritaria en el рIв.
} 
de la ciudad. Los que se emplazan en el centro histórico, que corresponden a la primera etapa, son los que albergan árboles inmensos. ${ }^{11}$ Por otro lado, los parques más grandes de la ciudad son los ecológicos, emplazados en la segunda etapa de crecimiento, ${ }^{12}$ y que originalmente fueron bancos de material en los que se formaron profundas hondonadas, quedando inservibles para la construcción de casas o edificios. En estos parques predominan juegos infantiles, mobiliario y caminos en cuya construcción destaca la vegetación de la región, aun cuando son austeros y con poco equipamiento.

Aunada a la proliferación de la vivienda en serie, se ha fragmentado y reducido el espacio para equipamientos que los fraccionadores ceden al ayuntamiento, espacios que albergan las áreas verdes (17\% del área vendible). Antes, los fraccionadores concedían espacios residuales que no podían lotificar ni vender, pero esta situación cambió cuando, de acuerdo con el Reglamento Municipal de Construcción, se permitió la reducción, en $40 \%$, de las áreas de donación a cambio de que los fraccionadores construyeran obras públicas, aunque realmente nunca se precisó en qué consistían dichas obras (Bolio, 2000).

Con el objeto de impulsar el deporte y ante la escasez de unidades deportivas, las administraciones municipales pasadas construyeron pequeñas canchas de usos múltiples en la mayoría de los parques recreativos de colonias y fraccionamientos, independientemente de las dimensiones de los parques. Si bien estas canchas subsanaron la carencia de espacios para deporte, los parques quedaron con mínimos espacios para áreas verdes.

Asimismo, el arbolado en las vías de circulación no es mucho más favorable que en los equipamientos. Los camellones, e incluso las banquetas de las principales avenidas, sistemáticamente se reducen para permitir mayor capacidad en el arroyo vehicular. De esta manera, los árboles en las vías de circulación tienen muy poco espacio y, viven sometidos a un fuerte estrés que les impide desarrollarse adecuadamente.

La distribución de las áreas verdes se asocia con las temperaturas de la ciudad. Entre los resultados arrojados por las diversas estaciones termo-

\footnotetext{
${ }^{11}$ Los principales parques construidos hasta mediados del siglo xx son: La Plaza de Armas, conocida como Plaza Principal o Plaza Grande, que se caracteriza por sus numerosos árboles de laurel (Ficus retusa L. var. nitida Miq.); el de Las Américas, con árboles como el balché (Lonchocarpus longistylus Pittier), utilizado en ceremonias mayas para preparar la bebida que toman en sus rituales, así como una serie de árboles provenientes de Asia y África (que presentan flores llamativas en determinadas épocas del año); el Parque del Centenario, que alberga especies nativas como el ramón (Brosimum alicastrum Swartz), ciricote (Cordia dodecandra A. DC.) y otras introducidas, como los laureles de la India (Ficus benjamina L.) Programa de Desarrollo Urbano de la Ciudad de Mérida, Ayutamiento de Mérida (2003: 25); y el parque de la Paz, al oriente de Mérida y frente al zoológico Centenario.

${ }^{12}$ Los parques ecológicos son Del poniente, con una superficie de 176,650 m²; Acuaparque, $107,000 \mathrm{~m}^{2}$ el del Oriente, con $87,500 \mathrm{~m}^{2}$; el Hormiguero, 30,000 $\mathrm{m}^{2}$ y el Japonés $25,500 \mathrm{~m}^{2}$.
} 
pluviométricas y el observatorio meteorológico se observa que las temperaturas tomadas en las zonas de reciente crecimiento habitacional, en el poniente de Mérida, presentan máximas de $34.3^{\circ} \mathrm{C}$ y $35.1^{\circ} \mathrm{C}$, en las estaciones del CICY y Gerencia Regional, respectivamente. En tanto que las temperaturas máximas más bajas se localizan en el norte y en el centro: $33.0^{\circ} \mathrm{C}$ y $33.3^{\circ} \mathrm{C}$, en las estaciones Emiliano Zapata y Mérida Centro, respectivamente, en aquellas zonas que presentan mayor arborización.

La diferencia entre las máximas temperaturas es de $2.1^{\circ} \mathrm{C}$. En nuestra ciudad no se produce el fenómeno de la isla de calor que generalmente se forma en las zonas centrales de las grandes ciudades (Morales et al., 2007; Carrillo, 2005), por el contrario, en Mérida, es en las áreas de reciente asentamiento donde se registran las máximas temperaturas. Sin embargo, el retardo térmico, es decir, cuando las temperaturas permanecen altas por más tiempo, sí se encontró en el centro de la ciudad y en la zona de sotavento, esta última localizada en el poniente (Canto y Pérez, 2003), zona con muy baja arborización.

\subsection{Normatividad}

La normatividad en el uso y aprovechamiento del territorio urbanizado se divide en dos vertientes: la primera consiste en los lineamientos generales para una adecuada organización y funcionamiento de los asentamientos humanos, tales como los planes y programas de desarrollo urbano. La segunda contiene los ordenamientos de carácter obligatorio e incluyen las leyes, decretos y reglamentos que establecen las bases para la obtención de permisos y licencias para la producción del espacio urbano.

Los más recientes programas de Desarrollo Urbano de la Ciudad de Mérida (Ayuntamiento de Mérida, 2010a) así como el Plan Municipal de Desarrollo (Ayuntamiento de Mérida, 2010b) emiten recomendaciones asociadas a las áreas verdes, tales como: Revisar la reglamentación de áreas verdes y de arborización; ejecutar programas de reforestación; crear y conservar los parques, jardines y áreas verdes que contribuyan al mejoramiento de la calidad del medio ambiente, y crear las condiciones que faciliten la convivencia humana y el bienestar físico de los usuarios; así como poner en marcha una serie de acciones que deberían implementarse para el cuidado del patrimonio natural.

Sin embargo, estos planes y programas de desarrollo, aun con la inclusión de los niveles normativos y estratégicos, no tienen un carácter legal obligatorio. Su particularidad es hacer recomendaciones generales sin llegar a plantear cuestiones específicas (Ayuntamiento de Mérida, 2010a: 19). 
Entre las leyes y reglamentos de carácter ambiental vigentes en la ciudad se encuentran la Ley de Protección al Ambiente del Estado de Yucatán (Gobierno del Estado de Yucatán, 1999) y el Reglamento de Protección al Ambiente y del Equilibrio Ecológico del Municipio de Mérida (Ayuntamiento de Mérida, 2005). La primera enuncia que debe prevalecer la construcción bioclimática que favorezca la reducción de emisiones de carbono, zonas de alta preservación ecológica y, en general, de un equilibrio sostenible, con la capacitación y formación de una cultura ambiental (Gobierno del Estado de Yucatán, 1999). En tanto que el Reglamento de Protección al Ambiente y del Equilibrio Ecológico señala en su artículo 98 que los árboles, principalmente los que se ubican en espacios públicos de la ciudad son propiedad del Ayuntamiento. El documento señala los lineamientos para la poda, derribo y trasplante de los árboles públicos, e igualmente proporciona una lista de las especies recomendadas y permitidas para su plantación, y especifica su porte (si es una especie pequeña, mediana o grande) y el lugar en que pueden ser plantadas según el tamaño de la calle, avenida o camellón. Pero no regula la existencia de superficies mínimas ni densidades arbóreas que los particulares, territorios y elementos de la estructura urbana deben respetar (Ayuntamiento de Mérida, 2005).

En la práctica, dos documentos norman la construcción de los espacios urbanos de Mérida, particularmente de los parques habitacionales, estos son, la Ley de Fraccionamientos de 1985 (Gobierno del Estado de Yucatán, 1985) y el Reglamento de Construcciones del Municipio de Mérida de 2004 (Ayuntamiento de Mérida, 2004). Ambos documentos contienen los criterios de usos del suelo a nivel urbano y de asentamiento habitacional, así como las proporciones de áreas verdes en relación a la superficie de construcción que los diferentes tipos de viviendas deben tener (Gobierno del Estado de Yucatán, 1985; Ayuntamiento de Mérida, 2004) (cuadros 1, 2 y 3 ).

Las normas de construcción de la vivienda y las superficies libres de construcción en los asentamientos de alta densidad (cuadro 1) son difíciles de cumplir, debido, en primer lugar, a que los metros cuadrados libres de construcción no están juntos, sino que se encuentran distribuidos de acuerdo al diseño de la vivienda, casi siempre en pasillos al frente y en la parte posterior de la casa. En segundo lugar, en la gran mayoría de los fraccionamientos el propietario recibe la casa sin cochera, área de lavadero y terraza, espacios que, al igual que otras ampliaciones, él construye paulatinamente sobre las áreas que de acuerdo al Reglamento deberían ser jardín.

En los fraccionamientos de baja densidad, con lotes de entre $300 \mathrm{y}$ $525 \mathrm{~m}^{2}$, en promedio, ubicados en las zonas donde vive la gente que 
percibe altos ingresos, las viviendas cuentan con áreas de servicio preestablecidas, por lo que el área libre de construcción generalmente permanece así, unas veces con jardines y otras con piso.

Para equipamientos urbanos, el Reglamento de Construcción señala, de manera imprecisa, que el área verde mínima ajardinada debe ser "de acuerdo a la zona de su ubicación” (Ayuntamiento de Mérida, 2004: 27). El mismo documento establece las áreas mínimas para los centros de barrio, subcentros urbanos y el centro urbano, 10, 15 y $20 \%$ del total del asentamiento, respectivamente, compartidas con los equipamientos y servicios. Sin embargo, la dificultad para aplicar la norma reside en que los subcentros y el centro urbano no están claramente identificados ni están representados en mapas.

En cuanto a los conjuntos habitacionales (cuadro 2), la Ley de Fraccionamientos establece $17 \%$ del área vendible como el máximo porcentaje de donación a los conjuntos habitacionales populares y debe compartirse con otros equipamientos, tales como la iglesia, la escuela, el mercado, las canchas deportivas, los juegos infantiles, etc.

\section{Cuadro 1 \\ Normas de construcción de vivienda}

\begin{tabular}{llcccc}
\hline Densidades & $\begin{array}{c}\text { Tipo de } \\
\text { vivienda }\end{array}$ & $\begin{array}{c}\text { Coeficiente de } \\
\text { ocupación del } \\
\text { suelo (cos) } \\
\text { máximo* }\end{array}$ & $\begin{array}{c}\text { Área minima } \\
\text { verde } \\
\text { jardinada } \\
(\%)\end{array}$ & $\begin{array}{c}\text { Sup. Minima } \\
\text { de lote }\left(m^{2}\right)\end{array}$ & $\begin{array}{c}\text { Área minima } \\
\text { verde } \\
\text { jardinada } \\
\left(m^{2}\right)\end{array}$ \\
\hline \multirow{2}{*}{ Baja } & Residencial & $60 \%$ & 20 & 525 & 105 \\
& Popular & $60 \%$ & 20 & 300 & 60 \\
Media & Media & $60 \%$ & 20 & 250 & 50 \\
\multirow{5}{*}{ Alta } & Popular & $60 \%$ & 20 & 250 & 50 \\
& Social & $75 \%$ & 12.5 & $160^{* *}$ & 20 \\
\hline
\end{tabular}

Fuente: Reglamento de Construcciones del Municipio de Mérida (Ayuntamiento de Mérida, 2004). * Relación entre la superficie de terreno ocupado con construcción techada y la superficie total del mismo (COS).

** Las dimensiones mínimas en Reglamento de Construccioneses de 8 x 20 metros y en el la Ley de Fraccionamientos (Gobierno del Estado de Yucatán, 1985) son 7 x 18 y por tanto la superficie mínima es de $126 \mathrm{~m}^{2}$.

Nota: De acuerdo al reglamento en caso de las áreas verdes jardinadas, no se considerarán las superficies con adopasto o pavimentos similares como complemento del porcentaje mínimo indicado. 


\section{Cuadro 2}

\section{Normas de fraccionamientos habitacionales}

\begin{tabular}{lcc}
\hline \multicolumn{1}{c}{ Tipo de vivienda } & \% de donación ${ }^{*}$ & Densidad hab/ha \\
\hline Residencial & 9 & $60-110$ \\
Residencial medio & 9 & $100-150$ \\
Residencial campestre & 12 & 50 y menos \\
Social & 15 & $150-300$ \\
Popular & 17 & $150-300$ \\
\hline
\end{tabular}

Fuente: Ley de Fraccionamientos del Estado de Yucatán (Gobierno del Estado de Yucatán, 1985). Nota: No se consideraron los fraccionamientos costeros y agropecuarios.

* Porcentaje de la superficie vendible.

\section{Cuadro 3}

Normatividad de vialidades En medios lineales

\begin{tabular}{|c|c|c|c|}
\hline Vialidad & $\begin{array}{c}\text { Area } \\
\text { vehicular }\end{array}$ & Banquetas & Superficie de área verde \\
\hline Avenida & 19 & $2.50 \mathrm{c} / 1$ & $\begin{array}{l}2 \text { metros de camellón y } 0.7 \\
\text { metro en banqueta }\end{array}$ \\
\hline Calle primaria* & 13 & $2.50 \mathrm{c} / \mathrm{l}$ & 0.7 metro en banqueta \\
\hline Calle secundaria o colectora & 10.5 & $1.5 \mathrm{c} / \mathrm{l}$ & $\begin{array}{l}\text { Se puede ubicar pocetas en } \\
\text { banqueta }\end{array}$ \\
\hline Calle terciaria & 7.5 & $1.5 \mathrm{c} / \mathrm{l}$ & $\begin{array}{l}\text { Se puede ubicar pocetas en } \\
\text { banqueta }\end{array}$ \\
\hline
\end{tabular}

Fuente: Ley de Fraccionamientos del Estado de Yucatán (Gobierno del Estado de Yucatán, 1985).

* Une el fraccionamiento con la traza urbana,

c/l cada lado del arroyo vehicular.

Las áreas verdes en las vías públicas contenidas en la Ley de Fraccionamientos (cuadro 3), que son muy limitadas en cuanto a la superficie, generalmente no se respetan. Realmente en pocas vialidades primarias que unen a los fraccionamientos con la traza urbana existente hay camellón, y las banquetas rara vez tienen las dimensiones que marca la norma. Sumado a lo anterior, un espacio de $70 \mathrm{~cm}$ de ancho solamente permite el crecimiento de un pequeño arbusto, y aun así únicamente quedarían $70 \mathrm{~cm}$ para el tránsito peatonal.

La Ley de Fraccionamientos del Estado de Yucatán indica que "las áreas verdes, jardines y camellones deberán ser entregados con las plantas y árboles de la región, según se especifique en el correspondiente Reglamento Municipal de Construcciones, así como sus tomas de riego, inde- 
pendientes del sistema de agua potable" (Gobierno del Estado de Yucatán, 1985: 3). Es la norma, pero en la práctica, se deja abandonada el área de donación, y a simple vista parece un lote baldío; de hecho, pueden pasar varios años, o hasta lustros, para que finalmente se construyan los primeros elementos de equipamiento y servicios, casi siempre la escuela, la iglesia o el parque infantil.

Fuera de los fraccionamientos, los reglamentos no mencionan los porcentajes de áreas verdes en equipamientos y vías de circulación, únicamente mencionan que debe ser "de acuerdo a la zona de su ubicación" (Ayuntamiento de Mérida, 2004: 27). Así como tampoco se contemplan lineamientos que conlleven al sano crecimiento de árboles y arbustos, por ejemplo, las variedades permitidas y las medidas mínimas de espacios libres de construcción que optimicen el desarrollo de la vegetación. Por otro lado, está el incumplimiento de la regla, como se verá en los casos de estudio.

\section{Tipología de cuatro asentamientos habitacionales}

En este apartado se analizan cuatro asentamientos habitacionales: los fraccionamientos San Antonio Cinta y Pacabtún y las colonias San Damián y San Antonio Xluch, seleccionados de modo que se aprecie la variedad de las tipologías de las viviendas habitadas por diferentes sectores sociales y que presentan contrastes en la densidad arbórea (figura II).

\subsection{San Antonio Cinta}

San Antonio Cinta ${ }^{13}$ es un pequeño fraccionamiento enclavado en la zona norte donde predomina la población de altos ingresos. ${ }^{14} \mathrm{La}$ densidad en el fraccionamiento es de 48.2 habitantes y 16.1 viviendas por hectárea. ${ }^{15}$ Las casas tienen alrededor de $250 \mathrm{~m}^{2}$ de terreno (10 metros de frente por 25 metros de fondo), de los cuales $20 \%$, cuando mucho, están sin construir; de modo que el área verde representa superficies de apenas $4 \mathrm{x} 4 \mathrm{~m}$, aproximadamente, y el resto son pisos. En una buena cantidad de casas predomina la vegetación en macetas, cuyo único fin es complementar el mobiliario y la decoración. Cabe destacar que de las 98 casas que confor-

\footnotetext{
${ }^{13} \mathrm{La}$ información corresponde a la totalidad del Área Estadística Básica (Ageb), no exclusivamente a la colonia. Los datos más recientes son del año 2000, el Censo de Población de 2010 no reportó este dato.

${ }^{14}$ El fraccionamiento abarca dos Agebs (Área Geoestadística Básica); en una, 54.6\% de la población ocupada recibía más de cinco salarios mínimos (sM), y en la otra, 48.2\%. La media de este sector es de 17.2\%. Los datos de ingresos corresponden al censo de población 2000.

${ }^{15}$ Los cálculos de densidades para los asentamientos analizados se hicieron con la información estadística por manzana del Inegi (2010) y mediciones de áreas por medio de Google Earth.
} 
man este fraccionamiento, solamente 12 tienen un árbol (con una copa de alrededor de $8 \mathrm{~m}$ de diámetro).

El único equipamiento es un pequeño parque de aproximadamente $1,000 \mathrm{~m}^{2}$, y más de la mitad está ocupado por el arenero con juegos infantiles. También cuenta con una avenida transversal de $200 \mathrm{~m}$, en cuyo camellón hay cinco árboles grandes (20 $\mathrm{m}$ de diámetro de copa, aproximadamente) y unos cuantos arbustos. El área de donación corresponde a $4.1 \%$ del área vendible. ${ }^{16}$ Los metros cuadrados de áreas verdes públicas por persona en este pequeño asentamiento, incluyendo el camellón, son 2.4 por habitante. ${ }^{17}$

\section{Figura II \\ Áreas verdes, arbolado y tipología de vivienda en cuatro asentamientos de Mérida}

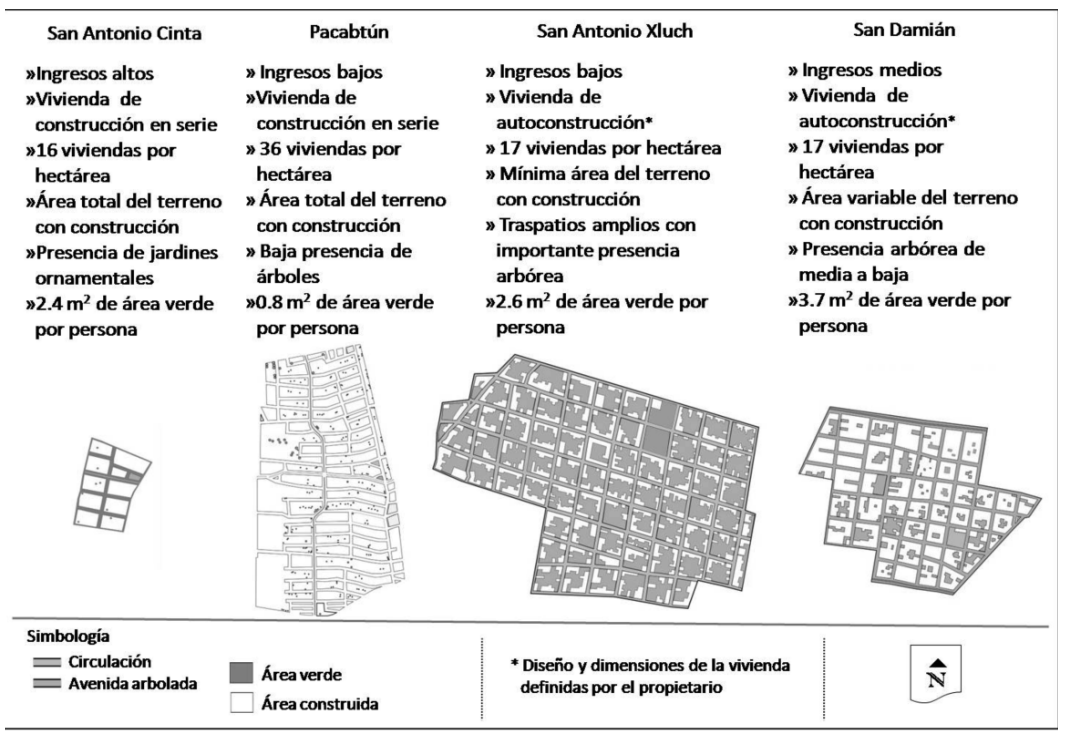

Fuente: elaboración propia con información tomada de Google Earth en diciembre de 2008 y trabajo de campo.

\subsection{Pacabtún}

Pacabtún se construyó en la década de 1970 y está habitado por familias de ingresos bajos. ${ }^{18}$ Este asentamiento es uno de los que tienen más alta

${ }^{16}$ La superficie vendible es el resultado de multiplicar el número de viviendas por los metros cuadrados del lote.

${ }^{17}$ Considerando $500 \mathrm{~m}$ de parque más $200 \mathrm{~m}$ de camellón y 294 habitantes.

${ }^{18}$ El fraccionamiento abarca dos Agebs, en uno 57.8 de la población ocupada recibía dos y menos salarios mínimos, y en el otro, $59.0 \%$. En tanto que la que recibía cinco y más representa 10 y $8.8 \%$, respectivamente (Inegi, 2000). 
densidad: 132.6 habitantes y 35.9 viviendas por hectárea. Los terrenos son de $8 \mathrm{~m}$ de frente por 20 de fondo. La edificación generalmente ocupa $80 \%$ del terreno, mientras que $20 \%$ restante se emplaza entre la calle y la casa, espacio que frecuentemente tiene piso y es utilizado como terraza o cochera, pero casi nunca cuenta con vegetación, si bien en algunas viviendas se encontraron árboles de limón o naranja agria, incluso en la parte posterior. De cualquier manera, el área verde es irrelevante en la totalidad del área construida, tal como lo constatamos con la evidencia del trabajo de campo y las fotografías aéreas.

Este fraccionamiento es considerablemente grande, lo conforman 1,843 casas. El área de donación que mide alrededor de $28,513 \mathrm{~m}^{2}$, y que representa $6.2 \%$ del área vendible, está ocupada por escuelas de preescolar, primaria y secundaria, mercados y pequeños parques emplazados en cuchillas desarticuladas que parecen más bien espacios residuales, y que en algunas manzanas se confunden con los lotes de las hileras de casas (figura II).

Precisamente llama la atención que en este asentamiento habitado por 6,803 personas no haya un verdadero parque recreativo central. El parque más grande es triangular y mide 2,400 $\mathrm{m}^{2}$. Bajo esta escasa disposición de áreas públicas, las áreas verdes se emplazan en pocos parques, no en todos, y abarcan 2,617 $\mathrm{m}^{2}$. Asimismo, el camellón que atraviesa el fraccionamiento, y mide $1,106 \mathrm{~m}$ de largo y $2.5 \mathrm{~m}$ de ancho, nada más tiene unos cuantos árboles que, en otras condiciones no representarían mucho, pero que en este asentamiento, dada la escasez de vegetación, se vuelven relevantes. En resumen, contabilizando parques y camellones, a cada habitante de Pacabtún le corresponde $0.8 \mathrm{~m}^{2}$ de área verde pública.

\subsection{San Antonio Xluch}

En San Antonio Xluch, los propietarios vendieron sus terrenos sin intervención de agentes inmobiliarios en la década de 1980, y las viviendas se fueron construyendo paulatinamente a lo largo de varias décadas. Su población corresponde al sector de bajos ingresos. ${ }^{19}$ La densidad de población es 67.9 habitantes y 16.6 casas por hectárea. Además, la colonia se emplaza en una de las zonas de la ciudad que presenta mayor arbolado.

La traza de calles en manzanas de 100x100 m, aunada a la densidad de viviendas y a las mínimas dimensiones de las construcciones por los exiguos ingresos de los residentes, permite amplios centros de manzana arbolados. En los frentes, entre la calle y la casa cuentan con espacios de tres metros,

\footnotetext{
${ }^{19}$ De los tres Agebs que abarca la colonia, en dos, $82.5 \%$ de la población ocupada recibe dos y menos salarios mínimos, y en el otro, $89.7 \%$ de los vecinos ocupados recibe este ingreso.
} 
aproximadamente, donde es muy común la presencia de grandes árboles, lo que genera un paisaje muy verde, de abundante vegetación. Los frutos de los árboles y las plantas que crecen en los solares de esta colonia son consumidos y aprovechados, dado que la vegetación es una mezcla que favorece tanto el ornato como la producción de alimentos.

Los equipamientos de la colonia, que ocupan una extensión de 22,000 $\mathrm{m}^{2}$, constan de escuelas de educación preescolar, primaria y secundaria, un parque, una cancha de beisbol, un centro comunitario y una iglesia. Entre estas áreas públicas, en general, llama la atención el conjunto de grandes árboles en las escuelas; la cancha de beisbol es de pasto, y únicamente la iglesia carece de vegetación, de modo que a cada habitante le corresponden $2.6 \mathrm{~m}^{2}$ de áreas verdes provenientes de los equipamientos. ${ }^{20}$ Esta reducida proporción de espacios verdes públicos en este asentamiento se compensa con los espacios arbolados privados. El trazo de las manzanas conlleva a la conformación de lotes que miden de 30 a $50 \mathrm{~m}$ de fondo, a diferencia de los fraccionamientos de viviendas en serie que tienen fondos de 16 a $25 \mathrm{~m}$ (dependiendo de si es zona residencial o popular). Las superficies resultantes de los solares arrojan una gran extensión de área vendible.

\subsection{San Damián}

La colonia San Damián fue creada durante el periodo 1950-1970, se ha ido poblando lenta y paulatinamente. Los vecinos perciben ingresos muy heterogéneos, por lo que este asentamiento se puede considerar como de clase media. ${ }^{21}$ La densidad de su población es de 54.5 habitantes y 16.8 viviendas por hectárea.

La traza de las manzanas de San Damián no sigue un patrón homogéneo. Las hay de 80 a $100 \mathrm{~m}$ por lado, y algunas son irregulares (figura II). Al igual que el trazo de calles, la dimensión de los lotes, la posición de la vivienda en el lote y el tamańo de ésta son muy variables, lo cual explica las diferencias en las superficies y densidad de las áreas verdes y arboladas en los centros de manzana. Encontramos lotes de 20, 10 y hasta de $6 \mathrm{~m}$ de frente, con fondos de hasta de $50 \mathrm{~m}$. Hay viviendas que cuentan con una sola habitación, y otras de ocho habitaciones y más, de una y dos plantas. Estas casas, las más grandes de la colonia, generalmente

\footnotetext{
${ }^{20}$ En esta colonia y en la de San Damián, el trazo de las manzanas conforma lotes de 30 a 50 metros de fondo, a diferencia de los fraccionamientos de viviendas en serie que tienen fondos de 16 a 25 metros (dependiendo de si es zona residencial o popular), esto arroja una gran extensión de área vendible. Sin embargo, ésta no se calculó debido a la diversidad de superficies de lotes particulares.

${ }^{21}$ De los dos Agebs que forman la colonia, en uno, 50.8\% de los habitantes recibía dos y menos salarios mínimos (sM), y $22.2 \%$ recibía cinco y más; en el otro, $51.1 \%$ recibía dos y menos SM, y $21.2 \%$, cinco y más SM (Inegi, 2000).
} 
no cuentan con árboles. El remetimiento de la vivienda es normalmente de $5 \mathrm{~m}$, aunque unas cuantas tienen hasta $10 \mathrm{~m}$, espacio que se utiliza para estacionamiento y para tener pequeńos arbustos.

Los equipamientos como la iglesia, escuelas y campo deportivo ocupan una extensión aproximada de 19,764 m², cuyas áreas verdes y con árboles suman $9,211 \mathrm{~m}^{2}$, cantidad que equivale a un total de $3.7 \mathrm{~m}^{2}$ de vegetación por habitante, porcentaje que aunado a la ausencia de árboles y plantas al frente de las casas en algunas calles, refleja un paisaje muy árido. De hecho, en el límite norte de la colonia se ubica una avenida que constituye el único elemento público con árboles grandes, aunque ajeno a este asentamiento.

En los casos aquí expuestos se aprecian claramente diferentes tipologías de asentamiento habitacional, y por eso se eligieron para documentar este estudio. Sus áreas verdes públicas por habitante van de 0.8 a $3.7 \mathrm{~m}^{2}$, y si a esta cantidad, en el contexto general de la ciudad, le sumamos los parques que por sus dimensiones y diseño tienen jerarquía urbana, ${ }^{22}$ y se encuentran en diferentes puntos, tenemos $1,113,100 \mathrm{~m}^{2}$, que divididos entre la población de Mérida en el 2010 , representan $1.3 \mathrm{~m}^{2}$ por persona, así que es evidente que ni al sumar los parques urbanos los habitantes logran tener los $9 \mathrm{~m}^{2}$ que marca la oms, ni qué decir de los 15 que seńala la onu.

De acuerdo al Reglamento de Construcción, las áreas verdes mínimas para el centro de barrio deberían tener 15\% del total del asentamiento. Sin embargo, como ya quedó demostrado en los casos estudiados, van de 0.5 a $2.0 \%$ del total de la superficie del asentamiento. En la norma, el área de donación destinada a áreas verdes, iglesia, escuela, mercado, cancha deportiva, juegos infantiles, etc., debe ser $17 \%$ del área vendible para los conjuntos habitacionales populares, y $9 \%$ para los de vivienda media y residencial, sin especificar qué superficie le corresponde a cada uno de los equipamientos (Gobierno del Estado de Yucatán, 1985).

\section{Análisis y discusión de áreas verdes y sostenibilidad en Mérida}

La oms establece que como mínimo en una ciudad debe haber $9 \mathrm{~m}^{2}$ de área verde por habitante y la onU menciona $15 \mathrm{~m}$, que son parámetros de los que disponemos para aproximarnos a una cobertura adecuada. En Mérida, de acuerdo con los datos del ayuntamiento tenemos $6.9 \mathrm{~m}^{2}$ por habitante, nuestros cálculos por colonia y fraccionamiento arrojan $5 \mathrm{~m}^{2}$ por habitante (incluyendo aquellos parques de jerarquía urbana),

\footnotetext{
22 El Parque de La Paz, el zoológico Centenario y el Parque de las Américas, que tienen superficies de $15,000,82,500$ y 32,400 m, respectivamente, además de los parques ecológicos: del poniente, que tiene una superficie de $176,650 \mathrm{~m}^{2}$; el Acuaparque, de 107,000 m; el del oriente, de $87,500 \mathrm{~m}$; el Hormiguero de $30,000 \mathrm{~m}$, y el Japonés de $25,500 \mathrm{~m}^{2}$.
} 
en San Damián, y 2.1 m en Pacabtún, el mejor y peor de los asentamientos habitacionales estudiados. Realidad, que lejos de mejorar, continúa con el predominio del modelo de vivienda unifamiliar horizontal y expansivo y con la ausencia de una normatividad clara, precisa y cabalmente respetada.

Esta situación, que podría ser grave en cualquier ciudad, en la nuestra es sumamente insalubre dadas las altas temperaturas durante siete meses del año. Como se ha indicado, las islas de calor no están en las áreas del centro, como en otras ciudades, sino en los fraccionamientos de la periferia de Mérida. La reducción de temperaturas mediante la distribución y densidad adecuada de la vegetación, específicamente de la cobertura arbórea, reduciría el consumo de energía (para aquellos que tienen posibilidad de tener aires acondicionados) y crearía ambientes menos agresivos para todos.

Las áreas verdes y arboladas en Mérida, independientemente de si es naturaleza o segunda naturaleza, son los elementos de la dimensión ecológica que brinda servicios ambientales y que permiten una ciudad sostenible. La falta de espacios verdes para la interacción social en Merida es claramente ilustrada por el fraccionamiento Pacabtún donde 6,803 habitantes tienen únicamente $0.8 \mathrm{~m}^{2}$ de área verde pública por habitante, incluyendo el camellón, los insignificantes y diseminados parques recreativos y demás equipamientos. Si bien este es el caso más grave, los otros asentamientos estudiados también tienen déficit de espacios de vegetación para recreación y socialización, tales son los casos de San Antonio Cinta que cuenta con 2.4 metros por residente, San Antonio Xluch, 2.6 y San Damián, 3.7, comprendidos en parques recreativos, equipamientos escolares y deportivos.

No obstante la insuficiencia, los asentamientos que no son fraccionamientos de vivienda en serie y cuyo establecimiento es anterior a la década de 1970 tienen un área central donde se concentran los equipamientos y los espacios de vegetación, a diferencia de los fraccionamientos en los cuales dichas áreas son espacios residuales de la lotificación. La ausencia de parques y jardines públicos que promuevan la convivencia y la interacción ha llevado al uso predominante de las plazas comerciales como espacios de intercambio social y recreativo. Lugares privatizados que reprimen la interacción entre los diferentes grupos sociales.

La falta de sitios de recreación al aire libre que promuevan el intercambio social ha conducido a una erosión del capital social, lo cual se manifiesta en las escasas agrupaciones vecinales que trabajan por intereses comunes. La carencia de espacios abiertos y parques para la activación física y el ejercicio (Ward, 2013) también se manifiesta en la salud física de los habitantes: Yucatán ocupa el primer lugar a nivel nacional con 
sobrepeso en la población infantil (36.3\%), el quinto lugar en adolescentes $(38.2 \%)$ y el cuarto en adultos $(74.4 \%)$. Situación que se agrava si se considera que México se ubica en los primeros lugares entre los países con mayor obesidad (Gobierno del Estado de Yucatán, 2013). Dolencia que no es del todo atribuible a la falta de áreas verdes pero es innegable que la ausencia de éstas conduce a las actividades recreativas sedentarias que contribuyen al sobrepeso y obesidad.

La construcción de vivienda, que se convirtió en uno de los sectores económicos más rentables y productivos de Mérida y del país (Bolio, 2007) se ha caracterizado por un modelo de vivienda unifamiliar horizontal poco creativo y repetitivo hasta el hartazgo, que deja poco espacio libre de construcción, así como por conjuntos habitacionales carentes de parques y áreas arboladas. Dinámica que ha desembocado en una ciudad dispersa con largos recorridos con su consecuente intensidad en el consumo de energía, islas de calor en los grandes fraccionamientos y escasez de espacios recreativos. La hegemonía del mercado de vivienda como elemento rector en la planeación urbana muestra la falta de equilibrio en las dimensiones de la sostenibilidad, armonía que es indispensable para la transición a la ciudad sostenible. Los gobiernos locales, lejos de alentar y promover nuevas propuestas de vivienda y asentamientos habitacionales que estén en armonía con el medio ambiente y la arborización, participan directa o indirectamente en la construcción de desarrollos inmobiliarios. Asimismo, la edificación de fraccionamientos de vivienda en serie también conviene a los gobiernos, pues de esa manera ostentan el título de "entidad eficiente en el plano del crecimiento económico", tanto por los empleos y el comercio que generan como por el hecho de dotar de vivienda a la sociedad. La organización y participación social que promueva la creación y mantenimiento de parques y jardines es prácticamente inexistente en nuestra ciudad. Fuera de los partidos políticos y agrupaciones religiosas contamos con pocas estructuras sociales o de vecinos. Hay erosión del capital social, retiro de vida colectiva, menos actividades cívicas, menos expectativas de la sociedad. Esto no es exclusivo de nuestra ciudad, en los países de América Latina hay poco capital social (UN-Habitat, 2009), que se asocia a la diversidad étnica (Florino, s.a.), pero también con la desigualdad económica y social.

La participación ciudadana es indispensable para la gobernanza. La falta de intervención y, por lo tanto, la distancia con la gobernanza relacionada a la arborización no distingue grupos socioeconómicos, cuando menos no se manifiestan en las diferentes zonas de Mérida, ciudad que esta claramente dividida por grupos de ingresos. Las diferencias de arborización por zonas se deben más a la tipología de los asentamientos que al interés que tienen los diferentes sectores por el incremento de la cober- 
tura vegetal. Situación que es evidente cuando se observan las zonas oriente y poniente de la ciudad, habitadas por la población de ingresos medios, que con pocas excepciones muestran baja cobertura arbórea (menos de 5\%), debido por un lado a la presencia de grandes fraccionamientos de vivienda en serie y por otro, porque los residentes, no muy limitados económicamente, tienden a ampliar sus casas.

La reglamentación y el manejo inapropiado del arbolado y áreas verdes urbanas dan cuenta de que no se tiene una cultura en pro de la naturaleza. Con pocas excepciones, la comunidad no demanda áreas verdes, no protesta ante la poda indiscriminada de árboles que se hace a favor del cableado público, ni se manifiesta ante el estrangulamiento de árboles en los camellones para ampliar el arroyo vehicular, tampoco cuando pasa la aplanadora que arrasa con todo ser vivo para preparar el terreno de los nuevos fraccionamientos. Ni qué decir del poco interés de la sociedad en tener, conservar o sembrar árboles en sus viviendas.

Es probable que la distancia con la naturaleza que tenemos sea más una cuestión de gobernanza y de capital social y no producto de la indiferencia ciudadana, es decir, los individuos pueden darle un alto valor a la naturaleza pero no existen los mecanismos de participación y organización para su fomento y defensa y, por otro lado, sus espacios privados son muy limitados para dar cabida a árboles y a vegetación. Esta es una interrogante que habría que aclarar en futuras investigaciones.

\section{Conclusiones}

La firma de tratados y acuerdos tendentes a la sostenibilidad ambiental a nivel global y las recomendaciones que hacen los organismos internacionales a las naciones para un adecuado desarrollo ambiental y social tienen que llevarse al ámbito local para dejar de ser sólo buenas intenciones. Es en esta escala donde se implementan los mecanismos de participación que lleven a una gobernanza efectiva que pueda equilibrar las dimensiones de la sostenibilidad ambiental, social y económica.

Para que haya una gobernanza efectiva en pro de la naturaleza es preciso partir del capital social del que disponemos y desarrollar acciones tendientes a fortalecerlo. La demanda de áreas verdes, su planeación, creación y mantenimiento son oportunidades para experiencias compartidas, alentar sentimientos de pertenencia y crear un lenguaje común basado en el cuidado de la naturaleza. Los parques, jardines y áreas arboladas podrían ser el punto de partida para el rescate y consolidación del capital social.

Es preciso restarle hegemonía al mercado y a las inversiones y darle mayor peso al desarrollo social y a la armonía ecológica. Las áreas verdes 
y el arbolado urbano representan solamente uno de los elementos de la sostenibilidad, esto tendría que hacerse extensivo a otros aspectos tendentes a una ciudad sostenible, tales como el consumo de productos y el manejo de desechos, el uso de energías renovables, la igualdad de oportunidades para todos los ciudadanos, entre otros.

\section{Bibliografía}

Alanís, Glafiro (2005), "El arbolado urbano en el área metropolitana de Monterrey", Ciencia UALN, VII (1), Universidad Autónoma de Nuevo León, Monterrey, pp. 20-32.

Ayuntamiento de Mérida (2003), "Programa de desarrollo urbano de la ciudad de Mérida 2003”, <http://www.merida.gob.mx/Ayunta2004/principal_desurbano.htm>, 18 de junio de 2006.

Ayuntamiento de Mérida (2004), "Reglamento de Construcciones del Municipio de Mérida”, DiarioOficial del Gobierno del Estado de Yucatán, 14 de enero de 2004, Mérida, Yucatán,<http://www. merida.gob.mx/municipio/portal/norma/contenido/pdfs/Archivos2004/construccion.pdf>, 15 de febrero de 2012.

Ayuntamiento de Mérida (2005), "Reglamento de Protección al Ambiente y del Equilibrio Ecológico del Municipio de Mérida”, Diario Oficial del Estado de Yucatán, 15 de diciembre de 2005, Mérida, Yucatán, <http://www.merida.gob.mx/municipio/portal/norma/ contenido/pdfs/Archivos2005/proteccion_ambiente.pdf>, febrero de 2012.

Ayuntamiento de Mérida (2010a), "Programa de desarrollo urbano de la ciudad de Mérida 2010", Dirección de Desarrollo Urbano, $<$ http://isla.merida.gob.mx/serviciosInternet/wsSIDU/html>, 10 de febrero de 2011.

Ayuntamiento de Mérida (2010b), "Plan Municipal de Desarrollo: Mérida 2010-2012", <http://www.merida.gob.mx/municipio/portal/ gobierno/contenido/plan_mun/plan_municipal-puntos.htmhttp://isla.merida.gob.mx/serviciosInternet/wsSIDU/html>, 10 de febrero de 2011. 
Barlett, Peggy (ed.) (2005), Urban place, reconnecting with the natural worl, The Massachussetts Institute of Technology Press, Cambridge, pp. 1-34.

Baycan, Tüzin y Peter Nijkamp (2009), "Planning and management of urban green spaces in Europe: comparative analysis", Journal of Urban Planning and Development, 135 (1), American Society of Civil Engineers, Nueva York, pp. 1-12.

Bolio, Jorge (2000), "La expansión urbana de Mérida”, Cuadernos de Arquitectura de Yucatán, núm. 13, Asociación de Revistas Latinoamericanas de Arquitectura, Mérida, pp. 1-11.

Bolio, Jorge (2007), "El escenario habitacional en la zona metropolitana de Mérida”, en Luis Ramírez (coord.), En la ruta del petróleo. Impactos de una eventual explotación petrolera en Yucatán, tomo II, Fundación Plan Estratégico de Mérida A. c., Mérida, pp. 119-194.

Canto, Raúl y María Milagrosa Pérez (2003), "Comportamiento térmico en la ciudad de Mérida”, en Lucía Tello-Peón y Alfredo Alonzo Aguilar (coords.), Evolución y estrategia del desarrollo urbano en la peninsula de Yucatán, Universidad Autónoma de Yucatán, Merida, pp. 173-194.

Carrillo, Luis (2005), "El efecto isla de calor", Gaceta Universitaria, pp. 8, <http://www.gaceta.udg.mx/Hemeroteca/paginas/388/388-8. pdf>, 20 de febrero de 2012.

Cerón, Ileana, Esther Sanyé, Jordi O. Solà, Juan I. Montero, Carmen Ponce y Joan Rieradevall (2013), "Towards a green sustainable strategy for social neighbourhoods in Latin America: Case from social housing in Merida, Yucatan, Mexico", Habitat International, vol. 38, Elsevier, Cambridge, pp. 47-56.

Colding, Johan, Jakob Lundberg y Carl Folke (2006), "Incorporating green-area user groups in urban ecosystem management", Ambio: Journal of the Human Environment, 35 (5), Royal Swedish Academy of Sciences, Stockholm, pp. 237-244.

Conagua (Comisión Nacional del Agua) (s.a.) Normales climatológicas para Mérida, Yucatán periodo 1981-2000, Servicio Meteoroló- 
gico Nacional, http://smn.cna.gob.mx/observatorios/historica/ merida.pdf, 10 de febrero de 2012.

Duhau, Emilio (1998), "Instancias locales de gobierno y gestión metropolitana”, en Gustavo Garza y Fernando Rodríguez (comps.), Normatividad urbanistica en las principales metrópolis de México, El Colegio de México, México, pp. 75-86.

Ernstson, Henrik, Sverker Sörlin y Thomas Elmqvist (2008), "Social movements and ecosystem services, the role of social network structure in protecting and managing urban green areas in Stockholm", Ecology and Society, 13 (2), Resilience Alliance, Stockholm, pp.1-27.

Fernández, Roberto (1994), "Problemáticas ambientales y procesos sociales de producción del hábitat: territorio, sistemas de asentamientos, ciudades", en Enrique Leff (comp.), Ciencias sociales y formación ambiental, UnAM-Gedisa Editorial, Barcelona, pp. 223-286.

Florino, Daniel (s.a.), "Sustainable cities and governance: What are the connections?", en Daniel A. Mazmanian e Hilda Blanco (eds.), Handbook of sustainable cities, Edward Elgar (en prensa).

Fonseca, Francisca (2008), "Procesos de ruptura y continuidad entre la naturaleza y sociedad en la ciudad moderna", Papers. Revista de Sociologia, núm. 88, Universitat Autònoma de Barcelona, Barcelona, pp. 141-151.

Freire, Milla (2007), "Sustainable cities: the role of local governance in managing change", ponencia presentada en el Symposium on A Global Look at Urban and Regional Governance: The StateMarket-Civic Nexus, Emory University, 18-19 de enero, Atlanta.

Frumkin, Howard (2005), "The health of places, the wealth of evidence," en Peggy Barlett, (ed.), Urban Place, Reconnecting with the Natural World, The Massachussetts Institute of Technology Press, Massachussetts, pp. 253-269.

García, Enriqueta (2004), Modificaciones al sistema de clasificación climática de Köppen para adaptarlo a las condiciones de la república mexicana, Universidad Nacional Autónoma de México, México. 
Garzón, Beatriz, Noemí Brañes, M. Laura Abella y Ana Auad (2004), "Vegetación urbana y hábitat popular: el caso de San Miguel de Tucumán”, Revista INVI, 49 (18), Universidad de Chile, Chile, pp. 21-42.

Gidlöf, Anita y Evy Öhrström (2007), "Noise and well-being in urban residential environments: The potential role of perceived availability to nearby green areas", Landscape and Urban Planning, 83 (2-3), Elsevier, London, pp. 115-126.

Girardet, Herbert (2001), Creando ciudades sostenibles, Ediciones Tilde, Valencia.

Gobierno del Estado de Yucatán (1985), "Ley de Fraccionamientos del Estado de Yucatán", Diario Oficial del Gobierno del Estado de Yucatán, 26 de Septiembre de 1985, <http://www.yucatan.gob. $\mathrm{mx} /$ gobierno/orden_juridico/Yucatan/Leyes/nr91rf1.pdf>, $25 \mathrm{de}$ marzo de 2011.

Gobierno del Estado de Yucatán (1999), "Ley de Protección al Ambiente del Estado de Yucatán", Diario Oficial del Gobierno del Estado de Yucatán, 23 de Abril de 1999, <http://www.yucatan.gob.mx/ gobierno/orden_juridico/Yucatan/Leyes/nr223rf1.pdf>, $25 \mathrm{de}$ marzo de 2011.

Gobierno del Estado de Yucatán (2013), Secretaría de Salud, <http://www. salud.yucatan.gob.mx/index.php?option=com_content\&task= view\&id=717>, 8 de mayo de 2013.

Gómez, Francisco, Nuria Tamarit y José Jabayoles (2001), “Green zones, bioclimatics studies and human comfort in the future development of urban planning", Landscape and Urban Planning, 55 (4), Elsevier, London, pp. 151-161.

Hardoy, Jorge, Diana Mitlin y David Satterthwaite (2001), Environmental problems in an urbanizing world, finding solutions for cities in Africa, Asia and Latin American", Earthscan Publications Ltd, London and Sterling.

Harvey, David (2010), "Organizarse para la transición anticapitalista", Forum Social Mundial 2010, Porto Alegre, <http://www.vientosur.info/documentos/Harvey.pdf>, 12 de octubre de 2010. 
Hill, Karen (2001), "New urbanism and nature: green marketing and the neotradicional community”, Urban Geography, 22 (3), Royal Geographical Society-Institute of British Geographers Urban Geography Research Group, London, pp. 220-248.

Inegi (Instituto Nacional de Estadística, Geografía e informática) (2000 y 2010), XII y XIII, Censo General de Población y Vivienda, INEGI, México.

James, P., K. Tzoulas, M.D. Adams, A. Barber, J. Box, J. Breuste, T. Elmqvist M. Frith, C. Gordon, K.L. Greening, J. Handley, S. Haworth, A.E. Kazmierczak, M. Johnston, K. Korpela, M. Moretti, J. Niemela, S. Pauleit, M.H. Roe, J.P. Sadler, C. Ward Thompson (2009), "Towards an integrated understanding of green space in the European built environment", Urban Forestry and Urban Greening, 8 (2), Elsevier, Oxford, pp. 65-75.

Köchli, Daniel y Peter Brang (2005), "Simulating effects of forest management on selected public forest goods and services, a case study", Forest Ecology and Management, 209 (1-2), Elsevier, Amsterdam, pp. 57-68.

Leff, Enrique (2002), Saber ambiental, sustentabilidad, racionalidad, complejidad, poder, Siglo XXI- PnUma-unam, México.

Lezama, José Luis y Judith Domínguez (2006), “Medio ambiente y sustentabilidad urbana", Papeles de Población, núm. 049, Universidad Autónoma del Estado de México, Toluca, pp. 154-176.

López, Ina (2008), “Arbolado urbano Mérida Yucatán y su relación con aspectos socioeconómicos, culturales y de la estructura urbana de la ciudad", tesis de maestría, Centro de Investigación y de Estudios Avanzados del Instituto Politécnico Nacional, Mérida.

López, Óscar y Héctor Toledo (2003), "Informes Técnicos. Estudio de la seguridad de las edificaciones de vivienda ante la incidencia de viento", Secretaría de Gobernación-Centro Nacional de Prevención de Desastres, México, pp. 1-79.

Maco, Scott y Gregory McPherson (2002), "Assessing canopy cover over streets and sidewalks in street tree populations", Journal of Ar- 
boriculture, 28 (6), International Society of Arboriculture, Champaign, pp. 270-276.

McMichael, Anthony (1999), "Urbanisation and urbanism in industrialised nations, 1850-present: implications for health", en Lawrence Schell y Stanley Ulijaszek (eds.), Urbanism, Health and Human Biology in Industrialised Countries, Cambridge University Press, Cambridge, pp. 21-45.

Morales, Carlos, Delfino Madrigal y Lidia González (2007), "Isla de calor en Toluca, México", Ciencia Ergo Sum, 14 (3), Universidad Autónoma del Estado de México, Toluca, pp. 307-316.

Neuvonen, Marjo, Tuija Sievänen, Susan Tönnes y Terhi Koskela (2007), "Access to green areas and the frequency of visits -A case study in Helsinki”, Urban Forestry and Urban Greening, 6 (4), Elsevier, Helsinki, pp. 235-247.

Newton, Julie (2007), "Well-being and the natural environment: a brief overview of the evidence", <http://www.fondazionesvilupposostenibile.it/documents/Riferimenti/NEWTON\%20Wellbeing\%20and\%20Nature\%2007.pdf>, 18 de abril de 2013.

NSII (Nacional Statical Institute of Italy) (2001), "Environmental sustaninability indicators in urban areas: an italian experiencia", Conference of European Statisticians, 1-4 octubre de 2001, Ottawa, <http:www.unece.org/stats/documents/2001/10/env/ wp.16.e.pdf>, 13 de julio de 2009.

oCDE (Organización para la Cooperación y el Desarrollo Económicos) (2011), "Towards Green Growth", Bulletin Desarrollo Sustentable, <http://www.oecd.org/document/10/0,3746,en_2649_37465_ 47983690_1_1_1_37465,00.html>, 8 de febrero de 2012.

Ojeda, Olga (1999), "La cooperación ambiental internacional en la era de la globalización”, en Ricardo Valero (coord.), Globalidad: una mirada alternativa, Centro Latinoamericano de la GlobalidadMiguel Angel Porrúa, México, pp. 97-150.

Oliveira, Sandra, Henrique Andrade y Teresa Vaz (2011), “The cooling effect of green spaces as a contribution to the mitigation of urban 
heat: A case study in Lisbon", Building and Environment, 46 (11), Elsevier, Amsterdam, pp. 2186-2194.

Pérez, Susana (2010), Segregación, recreación y calidad de vida en Mérida, Universidad Nacional Autónoma de México, México.

Perry, Thomas y Rizwan Nawaz (2008), "An investigation into the extent and impacts of hard surfacing of domestic gardens in an area of Leeds, United Kingdom”, Landscape and Urban Planning, 86 (1), Elsevier, London, pp. 1-13.

PNUma (Programa de Naciones Unidas para el Medio Ambiente) (2011), "Hacia una economía verde. Guía para el desarrollo sostenible y la erradicación de la pobreza", <http://www.pnuma.org/eficienciarecursos/documentos/GER_synthesis_sp.pdf>, 24 de enero de 2012.

Romero, Hugo, Ximena Toledo, Fernando Órdenes y Alexis Vásquez (2001), "Ecología urbana y gestión ambiental sustentable de las ciudades intermedias chilenas", Ambiente y Desarrollo, XVII (4), Centro de Investigación y Planificación para el Medio Ambiente, Santiago, pp. 45-51.

Satterthwaite, David (1997), "Sustainable cities or cities that contribuye to sustainable develpment?”, Urban Studies, 34 (10), University of Glasgow, Glasgow, pp. 1667-1691.

Sick, Thomas y Karsten Bruun (2007), "Do green areas affect health? Results from a Danish survey on the use of green areas and health indicators", Health and Place, 13 (4), Elsevier, Oxford, pp. 839-850.

Stabler, Linda, Chris Martin y Anthony Brazel (2005), "Microclimates in a desert city were related to land use and vegetation index", Urban Forestry and Urban Greening, 3 (3-4), Elsevier, Amsterdam, pp. 137-147.

Sullivan, William (2005), "Forest, savanna, city: evolutionary landscapes and human funetioning”, en Peggy Barlett (ed.), Urban place, reconnecting with the natural world, The MIT Press, Cambridge, pp. 237-252. 
Sorensen, Mark, Valerie Barzetti, Kari Keipi y John Williams (1998), "Manejo de las áreas verdes urbanas", Documento de las buenas prácticas, núm. 109, Banco Interamericano de Desarrollo, Washington, pp. 1-74.

Sullivan, William (2005), "Forest, savanna, city: evolutionary landscapes and human functioning", en Peggy Barlett (ed.), Urban place, reconnecting with the natural world, The MIT Press, Cambridge, pp. 237-252.

Tyrväinena, Liisa, Kirsi Mäkinenb y Jasper Schipperijnc (2007), “Tools for mapping social values of urban woodlands and other green areas", Landscape and Urban Planning, 79 (1), Elsevier, London, pp. 5-19.

Tzoulas, Konstantinos, Kalevi Korpela, Stephen Venn, Vesa Yli-Pelkonen, Aleksandra Kaźmierczaka, Jari Niemelac y Philip Jamesa (2007), "Promoting ecosystem and human health in urban areas using Green Infrastructure: A literature review", Landscape and Urban Planning, núm. 81, Elsevier, London, pp. 167-178.

UADY (Universidad Autónoma de Yucatán) (2013), Facultad de Ingeniería, Centro Meteorológico, http://www.unionyucatan.mx/ external?url=http://www.estacionclimatologica.ingenieria.uady. mx, 9 de mayo de 2013.

UN-Habitat (United Nations Human Settlements Programme) (2009), Planning Sustainable Cities, Global Report on Human Settlements 2009, <http://www.unhabitat.org/content.asp?typeid=19 $\&$ catid $=555 \&$ cid $=5607>, 8$ de mayo de 2013.

Van-Herzele, Ann y Torsten Wiedemann (2003), "A monitoring tool for the provision of accesible an attractive urban green spaces", Landscape and Urban Planning, 63 (2), Elsevier, London, pp. 109-126.

Wackernagel, Mathis y William Rees (1996), Our ecological footprint: reducing human impact on the earth, New Society Publishers, Gabriola Island.

Ward, Catharine (2013), "Activity, exercise and the planning and design of outdoor spaces", Journal of Environmental Psychology, núm. 34, Elsevier, London, pp. 79-96. 
Whitehead, Mark (2003), "Re analysing the sustainable city: nature, urbanisation and regulation of socio-environmental relations in the UK", Urban Studies, 40 (7), University of Glasgow, Glasgow, pp. 1183-1206.

Yang, Jun, Joe McBride, Jinxing Zhou y Zhenyuan Sun (2005), "The urban forest in Beijing and its role in air pollution reduction", Urban Forestry and Urban Greening, 3 (2), Elsevier, Amsterdam, pp. 65-78.

Recibido: 2 de julio de 2012.

Reenviado: 10 de abril de 2013. Aceptado: 19 de septiembre de 2013.

Susana Pérez Medina. Mexicana. Es doctora en urbanismo por la Universidad Nacional Autónoma de México. Actualmente es auxiliar de investigación en el Departamento de Ecología Humana del Centro de Investigación y Estudios Avanzados, unidad Mérida y profesora en la Universidad Marista de Mérida. Es miembro del Sistema Nacional de Investigadores, nivel I. Sus líneas de investigación son segregación urbana, áreas verdes y de recreación, sostenibilidad urbana, pobreza y desigualdad. Entre sus últimas publicaciones destacan: Segregación, recreación y calidad de vida en Mérida, Universidad Nacional Autónoma de México, México (2010); "Políticas públicas de combate a la pobreza en Yucatán 1990-2006, Gestión y Política Pública, Centro de Investigación y Docencia Económica A. C., México, pp. 291-329 (2011); "Condiciones habitacionales y pobreza en Yucatán. Un acercamiento etnográfico en contextos urbanos", Memoria de Congreso Nacional de Vivienda 2013, unam, México, pp. 117-136 (2013).

Ina Susana López Falfán. Mexicana. Maestra en ciencias en la especialidad de Ecología Humana por el Centro de Investigación y de Estudios Avanzados el Instituto Politécnico Nacional, Unidad Mérida, México. Actualmente estudiante del doctorado en ciencias del Instituto de Ecología, A. C. en Xalapa, Veracruz, México, en la Red de Ambiente y Sustentabilidad. Su línea de investigación es la ecología urbana, principalmente en relación con el arbolado urbano y con la percepción social de la diversidad en las ciudades. 